\title{
Temperature hysteresis of the resistivity for PbTe thermoelectric material
}

\section{$\mathrm{PbTe}$ 熱電材料の比抵抗の温度履歴}

\author{
Seiji YONEDA and Hiromasa T.KAIBE \\ Department of Electronics and Information Engineering, Tokyo Metropolitan University, 1-1, Minami- \\ Ohsawa, Hachioji-shi, Tokyo, 192-03, JAPAN \\ TEL:81-426-77-1111(EX.4463) FAX:81-426-77-2756 e-mail:yoneda@device.eei.metro-u.ac.jp, \\ kaibe@eei.metro-u.ac.jp, \\ Yoshio IMAI, Yoshikazu SHINOHARA and Isao A.NISHIDA \\ National Research Institute for Metals, 1-2-1, Sengen, Tsukuba-shi, Ibaraki, 305, Japan \\ TEL:81-298-59-2637FAX:81-298-59-2601e-mail:yoshi@nrim.go.jp,shinohara@nrim.go.jp, \\ albert@nrim.go.jp \\ Toshiaki MOCHIMARU, Kazuki TAKAHASHI and Teruo NOGUCHI \\ Vacuum Metallurgical Co., Ltd., 516 Yokota, Yamatake-cho, Yamatake-gun, Chiba, 289-12, Japan \\ TEL:81-0475-89-0151 FAX:81-0475-89-1469 \\ ( Received 7,0ctober 1996 Accepted 23, June 1997 )
}

\begin{abstract}
The resistivities $\rho$ of the solidified n- and p-type $\mathrm{PbTe}$ and plasma activated sintered n-type $\mathrm{PbTe}$ were measured as a function of temperature during heating and cooling cycles to progressively higher temperatures until $903 \mathrm{~K}$ in $\mathrm{Ar}$ atmosphere. The hysteresis of the temperature dependence of $\rho$ appeared for all specimens after heated above $703 \mathrm{~K}$, which indicates that the change of thermoelectric properties will occur during the operation as a thermoelectric generator. This phenomenon was more remarkable for the sintered specimen than that for the solidified one. However, X-ray analysis did not detect the evidence such as the apperance of the secondary phase or oxidation. Then, it is pointed out that the mechanism of the aging effect for $\mathrm{PbTe}$ can not be explained by solely the evaporation of constituents such as $\mathrm{Pb}, \mathrm{Te}$ and I.
\end{abstract}

Keywords : $\mathrm{n}$ - and p-type $\mathrm{PbTe}$, thermoelectric property, plasma activated sintering, aging phenomena, heating and cooling cycle, annealing

\section{I . INTRODUCT ION}

$\mathrm{PbTe}$ 系熱電材料は、1960年代前半宇宙用熱発電 器の主要材料として多用され、現在ではガスを熱 源とする地上用独立電源に使用されている。1これ らの発電器に使用される $\mathrm{n}$ 型PbTe系熱電材料は一 般に、キャリア濃度を $3 \times 10^{25} \mathrm{~m}^{-3}$ 付近に制御し、高 温端温度 600 〜 $950 \mathrm{~K}$ で使用される。 ${ }^{1,2} こ の$ 最大熱
電性能指数 $Z$ おび無次元性能指数 $Z T$ は $700 \mathrm{~K}$ にお いて $1.4 \times 10^{-3} \mathrm{~K}^{-1}$ および 1 程度である。均一組成の $\mathrm{n}$ 型 $\mathrm{PbTe}$ の $Z$ は最適温度 $T_{\text {opt }}$ で最大值 $Z_{\text {max }}$ を示し、 $T_{\text {opt }}$ 以上では $Z$ は急激に小さくなる。 $T_{o p t}$ と $Z_{\max }$ はと もにキャリア濃度の関数であり、キャリア濃度の増 加とともに $T_{\text {opt }}$ は高温側に移動し $Z_{\text {max }}$ は減少してい く。キャリア濃度が $5 \times 10^{24} \mathrm{~m}^{-3}$ から $7 \times 10^{25} \mathrm{~m}^{-3}$ ま で変化すると、 $T_{\text {opt }}$ は400〜 $800 \mathrm{~K}$ までの広い温度領 
域にわたつて制御でき、この温度領域で $Z_{\text {max }}$ は 1.7

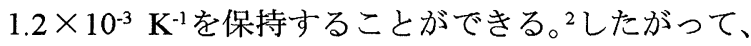
高温電極部と低温電極部の温度 $T_{h}$ と $T_{c}$ が決まればそ の間の素子のキャリア濃度を最適化する、すなわち 傾斜機能材料 (Functionally Graded Material, FGM) に することにより動作温度域内の平均の $Z$ は従来の単 一キャリア濃度の素子に比べ約1.5倍の向上が期待で き、変換効率 $\eta$ も $T_{h}=950 \mathrm{~K}, T_{c}=300 \mathrm{~K}$ のとき均一キャ リア濃度材料の $12.2 \%$ から $19 \%$ にまで高めることが できる。2

このように、PbTe系熱電材料のFGM化は、性能向 上に有効であり、今後の熱電材料の重要性を飛躍的 に高める可能性を秘めている。しかしながら異なる キャリア濃度をもつ材料の接合や電極の接合には拡 散接合が用いられると考えられ、そのとき素子は $1100 \mathrm{~K}$ 付近の高温まで昇温されることが必要とな る。 ${ }^{3,4}$ PutleyはPbTe単結晶による比抵抗 $\rho$ の温度依存 性の非可逆性を指摘し、797 Kまでの昇温前後で室温 における $\rho$ が $12 \%$ 減少し、さらに $919 \mathrm{~K}$ の昇温前後 では約 1 桁 $\rho$ が減少することを報告している。5また 最近、J.Rosenzweigらは熱電素子として使用される状 況を考慮し、密封ステンレス容器内でのPbTe焼結体 に対する熱処理効果について調べた。その結果、 $\mathrm{Na}$ 添加 $\mathrm{p}$ 型PbTe焼結体は $850 \mathrm{~K}$ まで昇温するこにより 熱電能とホール係数は変化しないが、 $\rho$ は増加する。 また、Brを添加したn型焼結体では、 $\rho$ の増加は $\mathrm{p}$ 型 焼結体に比べ小さいことを報告している。 ${ }^{6}$ この原 因として $\rho$ の非可逆性について雰囲気ガス中の残留 酸素が影響することを示唆している。6そこで、筆者 $ら^{7}$ は $1 \times 10^{25} \mathrm{~m}^{-3}$ のキャリア濃度をもつ $\mathrm{n}$ 型 $\mathrm{PbTe}$ 溶 製材料をステンレス容器内で $\mathrm{Ar}$ 雲囲気ガス圧 $1 \sim 3$ $\times 10^{5} \mathrm{~Pa}$ における $800 \mathrm{~K}$ までの昇温前後の $\rho$ の変化 を調べた。その結果、 $\rho$ は昇温後減少し、減少率はAr 圧の増加とともに大きくなることを明らかにした。

これらのことから、 $\mathrm{n} 、 \mathrm{p}$ 型PbTeの熱電特性が 850 $\mathrm{K}$ 付近での連続使用により変化することは明らかで あり、そのメカニズムを解明するとともに、この抑 制方法の確立が重要な課題である。そこで、本研究 では $\mathrm{n}$ 型および $\mathrm{p}$ 型PbTe溶製材料と $\mathrm{n}$ 型焼結体につ いて Arガス雲囲気における昇降温サイクル下での $\rho$ の温度依存性を調べ、昇温前後の試料の X線回折に よる同定を行ない、経時変化をもたらすメカニズム について検討を行った。

\section{II . EXPERIMENTAL PROCEDURE}

\section{A. Preparation of the solidified $\mathrm{PbTe}$}

純度 $6 \mathrm{~N}$ の $\mathrm{Pb}$ と $\mathrm{Te}$ を原子比 $1: 1$ になるように秤量 し、 $\mathrm{n}$ 型ドーパント剤として $0.5 \mathrm{wt} \% \mathrm{PbI}_{2}$ を内径 50 $\mathrm{mm}$ 、長さ $300 \mathrm{~mm}$ 透明石英管に $1 \times 10^{-3} \mathrm{~Pa}$ 以下で真 空封入した。溶解は摚挥溶解炬を用い、融液を 1273 $\mathrm{K}$ で $7.2 \times 10^{2} \mathrm{~s}$ ( 2 時間) 擋拌後、温度勾配 $0.8 \mathrm{~K} / \mathrm{mm}$ を保持したまま $2.8 \times 10^{-3} \mathrm{~K} / \mathrm{s}(10 \mathrm{~K} / \mathrm{h})$ で降温するこ とにより、 $\mathrm{n}$ 型 $\mathrm{PbTe}$ 溶製材料を作製した。得られた インゴットは直径 $50 \mathrm{~mm}$ 、高さ $30 \mathrm{~mm}$ であった（以 後、このインゴットをIngot 1 と呼ぶ)。Ingot 1 の上 部と下部から $\rho$ およ゙ホール係数 $R_{H}$ 測定用の短冊状 試料を切り出した。 $\rho$ および $R_{H}$ の測定はDC 法によ り行い、ペルチェ効果による誤差を極力取り除くた め高速、高分解法を用いた。 ${ }^{1}$ また、 $R_{H}$ 測定におけ る印加磁場は $0.33 \mathrm{~T}$ とた。Ingot 1 の $\rho$ は部 2.16

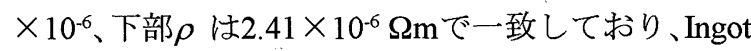
1 の均一性を確認した。さらに、Ingot 1 と同じ原料 およびドーパントを等組成、等重量に秤量し、文献 3 のFig. 2に示される内径 $16 \mathrm{~mm}$ と $50 \mathrm{~mm}$ の異径の透 明石英管からなり、先端角度約 $60^{\circ}$ の擋汼溶解用透 明石英管内に $1 \times 10^{-3} \mathrm{~Pa}$ 以下で真空封入した。擋拌 溶解凝固は融液を $1273 \mathrm{~K}$ で $7.2 \times 10^{3} \mathrm{~s}$ (2 時間) 擋 拌後、温度勾配 $0.8 \mathrm{~K} / \mathrm{mm}$ を保持したまま $2.8 \times 10^{-3}$ $\mathrm{K} / \mathrm{s}(10 \mathrm{~K} / \mathrm{h})$ で降温することにより行ない、直径 16 $\mathrm{mm}$ 、長さ約 $130 \mathrm{~mm}$ のインゴットを得た (このイン ヨ゙ットをIngot 2 と呼ぶ)。Ingot 2 の伝導型は全領域 にわたり $\mathrm{n}$ 型であったが、キャリア濃度 $n$ は成長開 始端の $2.1 \times 10^{25} \mathrm{~m}^{-3}$ から終了端の $2.8 \times 10^{24} \mathrm{~m}^{-3}$ まで 成長方向に沿って減少していた。また、比較試料と して $\mathrm{PbI}_{2}$ を添加していないp型PbTe溶製材料をIngot 2 と同じ方法で作製した。以後、これをIngot 3 と呼 ぶことにする。Ingot 1〜3 ともに粉末 X 線回折 $(\mathrm{Cu}-$ $\left.K \alpha_{1} 、 40 \mathrm{kV}-50 \mathrm{~mA}\right)$ によ、PbTe の単相であること を確認した。

\section{$B$. Preparation of the n-type sintered $\mathrm{PbTe}$}

Ingot 2 の成長端から 20,60,96 mmの各部分より厚 み10〜 $12 \mathrm{~mm}$ の輪切り状に切り出し、焼結体作製用 出発材料とした。これらの部分は $\rho$ が $2.84 \times 10^{-6}, 5.68$ $\times 10^{-6}, 9.46 \times 10^{-6} \Omega \mathrm{m} 、 n$ が $2.0 \times 10^{25}, 1.0 \times 10^{25}, 0.6$ $\times 10^{25} \mathrm{~m}^{-3}$ に対応する。各出発材料を粒径 $106 \mu \mathrm{m}$ 以 下、平均粒径 $42.5 \mu \mathrm{m}$ に粉砕し、 $\mathrm{Ar}+5 \% \mathrm{H}_{2}$ 混合ガス 1 $\times 10^{5} \mathrm{~Pa}(1 \mathrm{~atm})$ 雰囲気中でカーボンダイスを用い、 


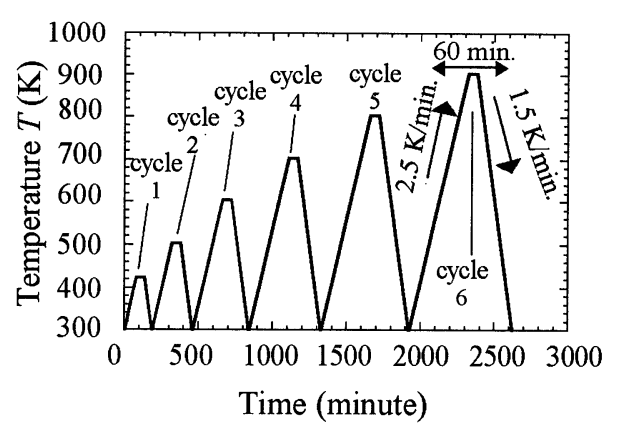

FIG.1.A series of heating and cooling cycles to progressively higher temperatures for measuring resistivity $\rho$. The temperature of each stage corresponds to $423,503,603,703,803$ and $903 \mathrm{~K}$ denoted by cycle No., respectively.

放電プラズマ焼結法によって n 型 $\mathrm{PbTe}$ 焼結体を作 製した。このとき焼結圧力 $4 \times 10^{7} \mathrm{~Pa}$ 、焼結中のダ イス温度 $769 \sim 781 \mathrm{~K}$ 、焼結時間 $60 \mathrm{~s}$ とした。得ら れた焼結体は直径 $15 \mathrm{~mm}$ 、高さ $3 \mathrm{~mm}$ のペレットで、 見掛け密度は各焼結体とも $99 \%$ 以上であった。以 後、20,60,96 mmの出発材料から作製された焼結体 ペレットをそれぞれ、 p-1, p-2, p-3 と呼ぶことにす る。 -1 -1にいてはクラックが入っていたため再粉 砕後、同条件で再焼結を行った。p-1〜3について も粉末 X 線回折により、PbTe の単相であることを 確認したのち、各ペレットからダイヤモンドカッ ターを用い、 $1 \times 2 \times 5 \mathrm{~mm}^{3}$ の短冊状試料を切り出 し、 $\rho$ および $R_{H}$ 測定用試料とした。

C. Evaluation of hysteretic temperature dependence of resistivity $\rho$ during a series of heating and cooling cycles to progressively higher temperatures

長さ $650 \mathrm{~mm}$ 、直径 $26 \mathrm{~mm}$ のステンレス製ステム 内にIngot 1, 3 およびp-2から切り出した測定用短冊 状試料をアルミナ板の上に $\mathrm{Al}_{2} \mathrm{O}_{3}$ 管で絶縁した白金 線で固定し、電極として直径 $50 \mu \mathrm{m}$ の白金線をス ポット溶接した。引き続き、ステム内を $1 \times 10^{-3} \mathrm{~Pa}$ 以下の真空にまで排気し、Ar ガス置換を行ったの ち、 $1 \times 10^{5} \mathrm{~Pa}$ の $\mathrm{Ar}$ ガスとともに封入した。その後、 $423 \sim 903 \mathrm{~K}$ の $100 \mathrm{~K}$ おきの各温度まで $4.2 \times 10^{-2} \mathrm{~K}$ $\mathrm{s}(150 \mathrm{~K} / \mathrm{h})$ で昇温し、各温度で $3.6 \times 10^{3} \mathrm{~s}$ (1 時間) 保持したのち室温まで $2.5 \times 10^{-2} \mathrm{~K} / \mathrm{s}(90 \mathrm{~K} / \mathrm{h})$ で降温 したときの $\rho$ を温度の関数として測定した。このと きの昇降温サイクルを Figure 1 に示す。試料の測温 はアルミナ板の下に挟み込んだ直径 $76 \mu \mathrm{m}$ の白金・

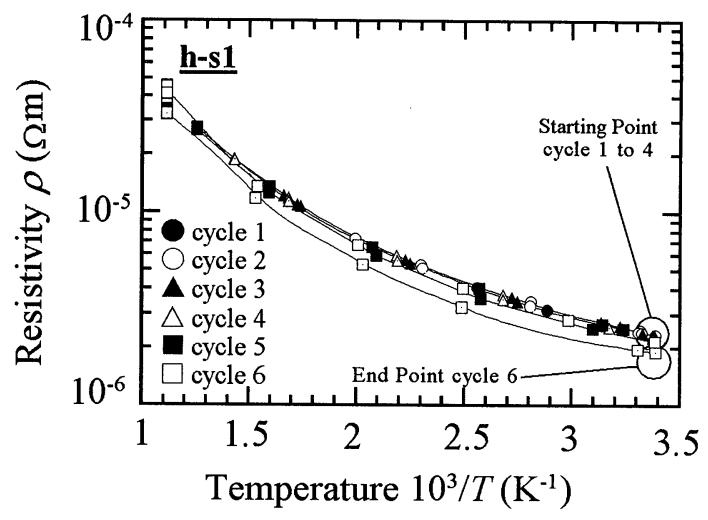

FIG.2.Temperature dependence of resistivity $\rho$ measured during a series of heating and cooling cycles as shown in FIG.1 for the n-type solidified PbTe (h-ml) in Ar atmosphere.

白金ロジウム熱電対で行った。以後、Ingot 1 と 3 か らの溶製材料および焼結体試料をそれぞれ h-s $1 、 h-$ s3、h-p と呼ぶことにする。また、これらすべてにつ

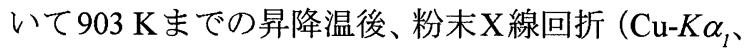
40kV-50 mA)により同定を行った。

\section{RESULTS AND DISCUSSION}

p-1、p-2、p-3 の室温における $\rho$ および $R_{H}$ から求 めたキャリア濃度 $n$ は、それぞれ $1.42 \times 10^{-3}, 1.03 \times$ $10^{-3}, 1.04 \times 10^{-3} \Omega \mathrm{m} 、 3.22 \times 10^{24}, 1.83 \times 10^{24}, 1.69 \times$ $10^{24} \mathrm{~m}^{-3}$ であり、出発材料である Ingot 2 の対応箇所 のそれらに比べ高抵抗化、低キャリア濃度化してい た。また、 $\rho$ と $R_{H}$ から求めた室温におけるホール移 動度 $\mu_{H}$ はいずれも $10^{-2} \mathrm{~m}^{2} / \mathrm{Vs}$ 以下であり、出発材料 から約 2 桁低減していた。プラズマ焼結法では出発 粉末に直接通電加熱するため、粉末粒子が接する箇 所では部分的に高温になることが予想され、その部 分でドーパントである $\mathrm{PbI}_{2}$ が揮発したことが低キャ リア濃度化の原因としてあげられる。プラズマ放電 焼結法に限らず、冷間プレス法で作製した $\mathrm{PbBr}_{2}$ 添 加 $\mathrm{n}$ 型 $\mathrm{PbTe}$ 焼結体についても出発材料に比べ高抵 抗化、低キャリア濃度化することが報告されてお り、 ${ }^{8}$ さらに $\mathrm{PbI}_{2}$ 添加 $\mathrm{n}$ 型 $\mathrm{Pb}_{0.95} \mathrm{Sn}_{0.05}$ Te焼結体につい ても溶製材料と比べ $\mu_{H}$ が低減し、 $\mu_{H}$ の温度依存性が 著しく異なることが指摘されている。7この原因の 1つとして、格子振動、イオン化不純物、点欠陥と いった溶製材料で支配的である散乱過程とともに粉 末化および焼結化により結晶粒界に形成されたエネ ルギー障壁が新たな散乱過程として加わり、 $\mu_{H}$ の低 減をもたらしたことが考えられる。6,9,10 


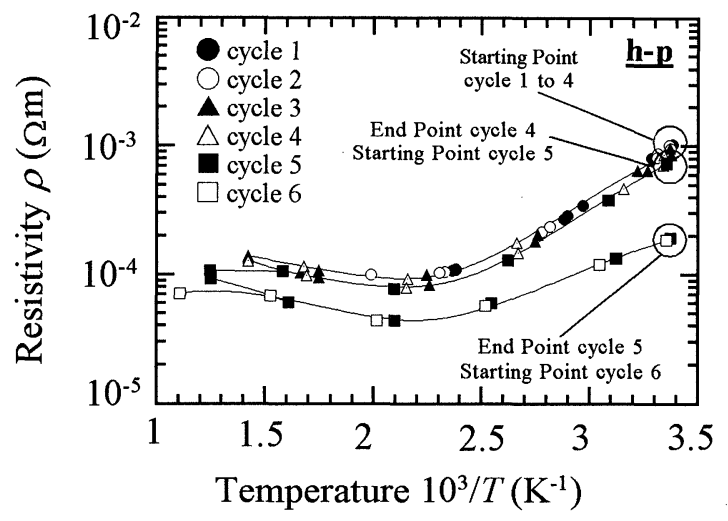

FIG.3.Temperature dependence of resistivity $\rho$ measured during a series of heating and cooling cycles as shown in FIG. 1 for the n-type plasma activated sintered PbTe (hp) in Ar atmosphere.

Figure 2 に溶製材料 h-ml の昇降温サイクルにおけ る $\rho$ の温度依存性を示す。昇温前の室温での值 $\rho_{R T}$ は $2.35 \times 10^{-6} \Omega \mathrm{m}$ であり、また、温度依存性も $603 \mathrm{~K}$ ま での昇温前後で変化がなく温度履歴は認められな かった。703 Kまでの昇温後の $\rho_{R T}$ は $2.26 \times 10^{-6} \Omega \mathrm{m}$ 、 $803 \mathrm{~K}$ では $2.16 \times 10^{-6} \Omega \mathrm{m}$ であった。さらに $903 \mathrm{~K} て ゙$ は $1.91 \times 10^{-6} \Omega \mathrm{m}$ にで減少していた。 $R_{H}$ から求め た室温におけるキャリア濃度 $n_{R T}$ は昇温前の $1.82 \times$ $10^{25} \mathrm{~m}^{-3}$ から $903 \mathrm{~K}$ までの昇温後の $2.44 \times 10^{25} \mathrm{~m}^{-3}$ ま で増加していた。

Figure 3 に焼結体 h-p の $\rho$ の温度依存性を示す。昇 温前の室温での值 $\rho_{R T}$ は $1.03 \times 10^{-3} \Omega \mathrm{m}$ であった。h$\mathrm{s}$ と同様に $703 \mathrm{~K}$ から $\rho$ の温度依存性に履歴が生じて おり、803 Kまでの昇温後で $\rho_{R T}$ は $1.89 \times 10^{-4} \Omega \mathrm{m} に$ まで減少していた。h-s1、h-p ともに $703 \mathrm{~K}$ 以上の昇 温により $\rho$ の温度依存性に履歴が現れるが、h-pの方 が h-s1 よりも $\rho$ の変化率が大きく、試料中に存在す る結晶粒界の体積増加が $\rho$ の履歴および低減化に寄 与するものと考えられる。

Figure 4 にはh-s3 の $\rho$ の温度依存性を示す。昇温前 の $\rho_{R T}$ は $4.70 \times 10^{-5} \Omega \mathrm{m}$ であった。 $503 \mathrm{~K}$ ま゙は昇温 前後で変化はなかったが、 $603 \mathrm{~K}$ では $9.33 \times 10^{-5} \Omega \mathrm{m}$ まで増加、 $703 \mathrm{~K}$ では $6.38 \times 10^{-5} \Omega \mathrm{m}$ に減少、 $803 \mathrm{~K}$ では再び $1.66 \times 10^{-4} \Omega \mathrm{m}$ まで増加していた。さらに それ以上の高温まで昇温を試みたが、白金リード線 の損傷が激しく、測定不能であった。h-s3 の伝導型 は $\mathrm{p}$ 型であり、昇温により蒸気圧の高い $\mathrm{Te}$ 泣試料表 面から解離するのであれば、n 型のh-s1やh-pのとき とは反対に昇温とともに $\rho_{R T}$ は単調に増加すると考え られる。しかしながら h-s3の $\rho_{R T}$ の変化は到達温度に

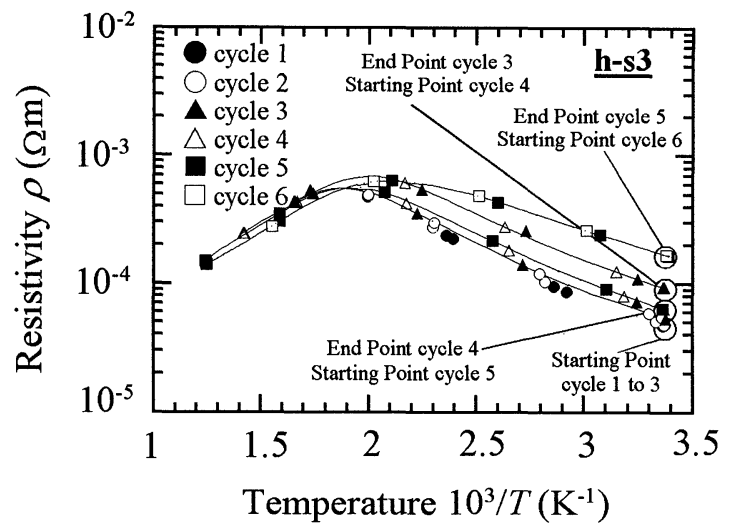

FIG.4.Temperature dependence of resistivity $\rho$ measured during a series of heating and cooling cycles as shown in FIG.1 for the p-type solidified PbTe (h-s3) in Ar atmosphere.

依存しており、 $\mathrm{Te}$ の解離が原因とは考えられない。

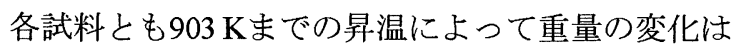

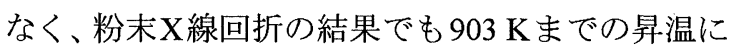
より第 2 相の析出や酸化の影響は認められなかつ たことから、のの温度履歴の原因解明にはさらに精 密な構造および組成分析の必要がある。

\section{CONCLUSIONS}

$\operatorname{Ar} カ 3 ス$ 雲囲気中における $\mathrm{n}$ 型および $\mathrm{p}$ 型PbTe溶 製材料と $\mathrm{n}$ 型焼結体の比抵抗 $\rho$ の昇降温サイクル

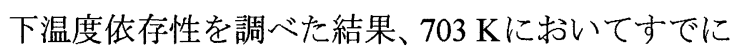
$\rho に$ 温度履歴が現れることがわかった。この現象は 焼結体の方が溶製材料より顕著に現れることから 結晶粒界の体積との関係が示唆された。しかし、X 線回折による同定結果では第 2 相の析出や酸化に よる影響は確認されなかった。また、PbTe の $\rho$ が 温度履歴をもつ原因については蒝気圧の高い $\mathrm{Te}$ の 試料表面からの解離だけでは説明できないことか ら、さらに詳細な組成および構造分析の必要性が 指摘された。

\section{謝辞}

$\mathrm{X}$ 線回折実験に協力していただいた育英工業高 等専門学校大杉功博士、小島勉教授に謝意を表す る。本研究は平成 8 年度科学研究費補助金重点領域 研究「傾斜機能材料の物理・化学」の援助により行 われた。 


\section{REFERENCES}

${ }^{1}$ K.Uemura and I.A.Nishida, Thermoelectric Semiconductors and their applications (in Japanese), Nikkan-Kogyo Shinbun-sya,1988.

${ }^{2}$ I. A. Nishida, Materia Japan, 35, 943(1996) in Japanese.

${ }^{3}$ Y.Imai, Y.Shinohara, I.A.Nishida, H.T.Kaibe, K.Sato, H.Kohri and I.Shiota, in Proceedings of FGM'95, Tokyo, 1995, edited by I.Shiota, pp.101-106.

${ }^{4}$ M.Weinstein and A.I.Mlavsky, Rev.Sci.Instr., 33, 1119(1962).

${ }^{5}$ E.H.Putley, Proc.Phys.Soc.London, 68(1954)22.
${ }^{6}$ J.Rosenzweig, J.Zhang and U.Birkholz, phys. stat. sol. (a)83, 357(1984).

${ }^{7}$ H.T.Kaibe, S.Yoneda, Y.Shimazaki, T.Okumura, Y.Imai, I.A.Nishida and I.Shiota, Journal of Advanced Science, 7, 157(1995).

${ }^{8}$ R. Breschi, A. Olivi, A. Camanzi and V. Fano, J. Mater. Sci., 15, 918(1980).

${ }^{9} \mathrm{~J}$. Yoshino, in Proceedings of FGM'94, Tokyo, 1994, edited by I.Shiota, pp.223-228.

${ }^{10} \mathrm{~J}$. Yoshino, in Proceedings of FGM'95, Tokyo, 1995, edited by I.Shiota, pp.66-64. 